\title{
Health, Quality of Life and GDP: An ASEAN Experience
}

R. Ramesh Rao (Corresponding author)

Faculty of Economics \& Administration

University Malaya

50603 Kuala Lumpur

Malaysia

Tel: +6017-8792159Ｅ-mail: rameshdivan@yahoo.com

Rohana Jani

Department of Applied Statistics

Faculty of Economics \& Administration

University Malaya

50603 Kuala Lumpur

Malaysia

Tel: 603-79673747_E-mail: janir59@yahoo.com

Puvanesvaran Sanjivee

Faculty of Economics \& Administration

University Malaya

50603 Kuala Lumpur

Malaysia

Tel: +6012-3795730Ｅ-mail: puvanesvaran@gmail.com

\begin{abstract}
Governments all over the world would like to improve the well being of its citizen. One aspects of well being can be seen through the quality of life (QoL) a person enjoys. Measuring and determining what is QoL is not an easy task. In this paper, using per-capita income as the yardstick for QOL, and the role of government through the way it spend its public money would be able to tell how ASEAN governments' expenditure influences the QoL. Particularly government expenditure on health signifies the commitment of a government in improving the QoL. QoL can also be seen through the availability of health care in country. When health care improves, life span and earning abilities will raise too. It is the government's responsibility in providing the best health care to the people. Government's commitment can be gauged through the amount it spends on these items. At the same time government spending would bring spillover effects in terms of raising per-capita income, which reflects the QoL. Using data on government expenditure of ASEAN countries for the last 15 years, it would be possible to determine on what extent expenditures on health do influence the per-capita income. Initial findings reveal that the impact of both these government expenditures on per-capita income is not the same for all the ASEAN countries.
\end{abstract}

Keywords: Quality of life, Government Expenditure, Per-Capita Income, Granger Causality

\section{Introduction}

It is well recognized that residents of richer countries have generally higher Quality of Life (QoL) than residents of poorer countries. The quality of health and health services are also better in richer countries. As such, one can argue that Gross Domestic Product (GDP) per capita and health expenditure, which is a measure of the quality of health service (UN, 2007), are positively correlated.

In some countries, population increase is followed by an increase in education and health expenditure, which is reflected in higher government expenditure (Sinha, 1998). QoL can also be measured through health expenditure per capita. Any governmental expenditure on health will wriggle down to the people. At the same time, as the QoL in a society improves the productivity in that country too would increase. This would be reflected in the growth rate of per capita GDP. This raises the question on the nature of the causality between QoL and per capita GDP. 
In this paper, we hope to study the relationship between QoL and GDP per capita in developing countries. Which affects the other? Does QoL affect GDP per capita or vice versa? The ASEAN countries are covered in this study; principally Indonesia, Malaysia, Singapore, Philippines and Thailand. Government expenditure on health is used as the proxy for QoL.

To our knowledge, there has not been any significant study relating health expenditure to GDP and QoL. We would be using Granger Causality test to study this link. The remainder of this paper is organized as follows. Section II briefly discusses what QoL is and some of the means for measuring QoL. QoL will be linked to government expenditure. Section III describes the methodology and data used in this paper. Section IV would review the results and discuss about the findings. The conclusion is presented in Section $\mathrm{V}$

\section{Literature Review}

QoL is a very important measure to study the success of socioeconomic policies in a country. It can also be used as a tool for policy analysis to identify inequities and measure progress. Economic indicators alone cannot be used to explain the broader QoL within a society. Various models have been developed to measure QoL, and this has been a highly debated issue. Dijkers (2003) argued that many investigators bypass the difficulty of defining what QoL means and go right ahead with developing a measure or selecting a published measure to use in their research. Wish (1986) argued that researchers were giving equal weightage to all the components without taking into consideration the perception of the local population.

United Nations (2007) focuses on Human Development where individuals can create real choices for themselves by a sufficient income, an education, good health and living in a country that is not governed by tyranny. The United Nation's Human Development Index (HDI) was developed in 1990 and is used to indicate the development status of a country. The HDI measures life expectancy, literacy, education and standard of living. The HDI critics claim that the HDI indicators are too few and too arbitrarily chosen (Berenger \& Verdier-Chouchane, 2007). The Economist measures QoL using an index consisting of nine indicators: 1) material well-being, 2) health, 3) political stability and security, 4) family life, 5) community life, 6) climate \& geography, 7) security, 8) political freedom and 9) gender equality (Kenny, 2005).

A random glance at the top 20 ranked countries by HDI, shows that countries with high QoL and Life Expectancy Index (LEI) have a high GDP per capita (UN, 2006). This is also evident among the ASEAN countries. Higher ranked countries on the HDI generally display higher LEI, implying better health, and higher GDP per capita.

Whatever the debate on the definition and the measurement on QoL, health is a key component of any such measurement. The World Health Organisation's constitution defines health to constitute "a state of complete physical, mental and social well-being and not merely the absence of disease or infirmity" (WHO, 1946). Government expenditure on health is a critical component of any health system (United Nations, 2007). Any improvement in the health system, via government expenditure, should improve QoL.

The general consensus among researchers is that there exists a strong and positive correlation between healthcare expenditure and GDP (in real per capita terms) at the aggregate level (Auster \& Sarachek, 1969). Figure 1 shows that the ratio of "Total expenditure on health" as a percentage of GDP is between $2 \%$ and $4.5 \%$ for the selected ASEAN countries. This ratio is growing for some countries, while it fluctuates for others.

The ratio for Malaysia in Figure 1 had been generally on the rise even after the financial crisis 1997. Health care expenditure can also be regarded as an investment in human capital (Grossman, 1972). Smith \& Abdullah (2004) have argued that a good human resource management used by Malaysia during the financial crisis had helped the country in overcoming the turmoil.

This scenario questions the causality relationship between government expenditure on health and GDP. Does greater healthcare expenditure result in higher GDP or does higher GDP result in greater healthcare expenditure (Devlin \& Hansen, 2001)? Often healthcare is treated as a share of GDP (Docteur and Oxley, 2003). Wagner's "Law of increasing State Spending" would interpret that the increase in economic activities leads to an increase in government activities, which in turn results in the rise of public expenditure (Liu \& Chang et.al, 2005).

\section{Methodology}

Any measurement of QoL should have 2 main ingredients, consisting of the operational or environmental component and psychological aspect (Wish, 1986). Although usage of both these components is ideally recommended, the purpose of the study is the key factor that determines the choice of components used. In studies where the sole purpose is to compare between 2 locations, then the latter component, i.e psychological, could pose a problem. As Wish (1986) puts it, it would be like comparing between apples and oranges. In this study, we will only consider the environment component when computing QoL. 
In this study, GDP per capita (GDP) and health expenditure by the government is used to measure QoL in a country. GDP is often used to measure the standard of living or QoL. It is used as the proxy for QoL when comparing between countries (Becker, Philipson \& Soares, 2005; Be'Renger \& Verdier-Chouchane, 2007). It is not the purpose of this paper to look at the distribution of GDP across a country. Instead, this paper only wishes to explore the causal relationship between GDP and health expenditure in the selected countries.

Another indicator that which could be used instead of GDP is Gross National Product per capita (GNP). Many studies which have used GNP and GDP had yielded similar results. For the 5 countries in this study, we found that the correlation between GDP and GNP to be high.

Another measure of QoL is health function or health availability to a person (Russell, Hubley, et al, 2006). Any expenditure by the government will have a spillover effect on the economy and people of a country. In this aspect, the amount a government allocates and spends on health will have a bearing on the population who are ultimately the recipient of the service itself.

Devlin \& Hansen (2001) using data from 20 OECD countries found out that "Granger Causality" between health expenditure and GDP could be both ways, one way or none. Using the same approach, this study aims to explore if health expenditure "Granger cause" GDP, GDP Granger cause health expenditure or the relationship is bidirectional. It could also be possible that there is no statistically significant relationship between the two.

If health expenditure causes GDP and GDP does not cause health expenditure, it is said that a unidirectional causality exists from health expenditure to GDP. If GDP causes health expenditure and health expenditure does not cause GDP, it is said that a unidirectional causality exists from GDP to health expenditure. On the other hand, bidirectional causality is said to be occurring if health expenditure causes GDP and vice-versa. However if health expenditure does not cause GDP and GDP also does not cause health expenditure, then the Granger Causality between them is said to be statistically independent or related contemporaneously.

The causality between GDP and health expenditure is undertaken by running the following regression. The null

hypothesis "Health expenditure does not cause GDP" is tested by running the following regression

$G D P_{t}=\alpha+\sum_{j=1}^{p} \beta_{j}(G D P)_{t-1}+\sum_{j=0}^{P} \lambda_{j} H_{t-j}+\varepsilon_{t}$

The null hypothesis that "GDP does not cause Health" is tested by the following regression

$H_{t}=\alpha+\sum_{j=1}^{p} \beta_{j} H_{t-1}+\sum_{j=0}^{P} \lambda_{j}(G D P)_{t-j}+\varepsilon_{t}$

Where GDP $=$ Gross Domestic Product

$\mathrm{H}=$ Government Health Expenditure

$\mathrm{t}=$ number of observation

$\mathrm{j}=1 \sim \mathrm{m}, \mathrm{m}$ is the lagged time value.

In this study, 5 ASEAN countries are selected. They are Indonesia, Malaysia, Philippines, Singapore and Thailand. GDP and government health expenditure data is obtained from Asian Development Bank. For all countries, except Thailand, data was available from 1981-2005. Thailand data was only available from 1995-2003. As the sample size is small, we have set the lag (m) at 5 for Indonesia, Malaysia, Philippines and Singapore. For Thailand the lag (m) has been set at 2. This approach is recommended for sample sizes smaller than 200 (Guilkey and Salemi, 1982). The comparisons were made using per capita GDP and per capita health expenditure data.

\section{Estimation Results and discussion}

The results of the regression and the F-test are shown in Table 1 and 2. Table 3 depicts the summary of the results. All the countries in the sample, excluding Philippines, display some form of causality between GDP per capita and health expenditure per capita. The fact that many of the countries show significant GDP Granger Cause health is supported by Adolph Wagner's proposition. Wagner's "Law" proposes that a state will increase its government expenditure relatively to the national income (Henrekson, 1993).

Any change in the amount of health expenditure will influence the per capita health expenditure in a country. Since QoL is related to health expenditure per capita, then QoL too will change. Figure 2 shows that the change in QoL in Malaysia is less volatile compared to Singapore's.

Table 3 shows that only Indonesia and Thailand have a bidirectional Granger Causality between GDP and health expenditure. In both these countries, government health expenditure exhibits an increasing trend. However, the involvement of Thailand government looks higher than Indonesia's government involvement. (See Figure 3 and 4) 
This could be attributed to the fact that government intervention in health services in Thailand is of a greater necessity as the market has failed in providing these services. This is in line with Musgrove et.al (2002) argument that government intervention is needed when the market fails to fulfill the need of the people.

One conjecture that could be used is the proportion of AIDS patients in Thailand is significantly higher than any other country in the region (Refer to Table 4). The cost of treating AIDS patients is higher than for any other ailment. . For instance, the annual cost of treating an AIDS patient in US is about US $\$ 38,300$ per annum but the cost of lifetime treatment of a breast cancer patient is only US $\$ 52,000$ (Altman, 1992). This high cost of treatment, hinders many patients from seeking private medical treatment.The market in Thailand could have been unable to support AIDS treatment. This could have forced the Thailand government to have greater involvement in providing the necessary health services.

In the case of Indonesia, private involvement is more dominant than government in health expenditure. This could be due to fact that Indonesia, which consists of many islands, faces diseconomies of scale in the provision of health services by the government. As such many Indonesians are forced to rely on private medical services.

Although government involvement in health expenditure is increasing in Indonesia (as shown in Figure 3), many Indonesians are deprived of proper health care services because of poverty. WHO (2006) estimates that US\$30 - US\$40 is needed for per person in providing essential health care. However in Indonesia this is only US\$16, and $63 \%$ of it originates from out-of-pocket expenditures.

The odd result in this study is Philippines. There is no Granger causality in any direction between health expenditure and GDP. However it is interesting to note that Philippines is the major supplier of health related workforce to the world (Bach, 2003). The economic loss due to exporting health related workforce is offset by the money repatriated back home by them (Bach, 2003).

It is beyond the scope of this study to evaluate the impact caused by this "repatriation on income by the health care workers" to the Philippines economy. We believe that if this income was included as health expenditure, although this is against the norm, the results shown in Table 3 and 4 would be different.

\section{Conclusion}

Our study shows that economy performance of a country is important in determining QoL. However not all the countries used in this study conform to this notion. Other than Philippines, the other countries' support this proposition.

If QoL in a country is determined through the amount spend on health expenditure, then all the countries do exhibit an increase. However when taking into consideration the population increase, then health expenditure per capita is able to give a better picture of QoL in a country.

Malaysia's and Singapore's results show a unidirectional Granger Causality. Meanwhile, Thailand's and Indonesia's results show bidirectional Granger causality. Different causal relationships between GDP and health expenditure do not imply that QoL is necessarily higher in countries exhibiting any specific type of causal relationship.The only exception in this study is Philippines. There is no Granger Causality between GDP and health expenditure in this country.

\section{References}

Altman, L. K. (1992). Cost of Treating AIDS Patients Is Soaring. The New York Times. New York.

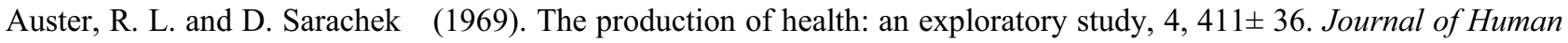
Resources 4: 411-447.

Bach, S. (2003, July). International migration of health workers: Labour and social issues. Retrieved 27 November 2007, from http://www.ilo.org/public/english/dialogue/sector/papers/health/wp209.pdf.

Becker, G. S., T. J. Philipson, et al. (2005). The Quantity and Quality of Life and the Evolution of World Inequality. American Economic Review 95(1): 277-291.

Bérenger, V. and A. Verdier-Chouchane (2007). Multidimensional Measures of Well-Being: Standard of Living and Quality of Life Across Countries. World Development 35(7): 1259-1276.

Chang, T. (2002). An econometric test of Wagner's law for six countries based on cointegration and error-correction modelling techniques. Applied Economics 34(9): 1157-1169.

Devlin, N. and P. Hansen (2001). Health care spending and economic output: Granger causality. Applied Economics Letters 8(8): 561-564.

Dijkers, M. P. (2003). Individualization in quality of life measurement: Instruments and approaches. Archives of Physical Medicine and Rehabilitation. 84: 3-14.

Docteur, E. and H. Oxley. (2003). Health-Care Systems: Lessons From The Reform Experience. OECD Health Working Papers Retrieved 28 November 2007, from http://www.oecd.org/dataoecd/5/53/22364122.pdf. 
Grossman, M. (1972). On the concept of health capital and the demand for health. Journal of Political Economy, 80.80(2): 223-255.

Guilkey, D. K. and M. K. Salemi (1982). Small Sample Properties Of Three Tests For Granger-Causal Ordering In A Bivariate Stochastic System. Review of Economics \& Statistics 64(4): 668-681.

Henrekson, M. (1993). Wagner's Law - A Spurious Relationship? Public Finance 46(3): 15.

Kenny, M. (2005, 28 November 2007). The Economist Intelligence Unit's. quality-of-life index. from http://www.economist.com/media/pdf/QUALITY_OF_LIFE.pdf.

Liu, J., T. Chang, et al. (2005). An Empirical Note on Testing the Wagner's Law for China: 1979-2002. The Business Review. 3(2): 131-134.

Musgrove, P., R. Zeramdini, et al. (2002). Basic patterns in national health expenditure. Bulletin of the World Health Organization. 80: 134-146.

Russell, L. B., A. M. Hubley, et al. (2006). Does Weighting Capture What's Important? Revisiting Subjective Importance Weighting with a Quality of Life Measure. Social Indicators Research 75(1): 141-167.

Sinha, D. (1998). Government Expenditure and Economic Growth in Malaysia. Journal Of Economic Development. 23(2): 71-80.

Smith, W. and A. Abdullah (2004). The Impact of the Asian Financial Crisis on Human Resource Management in Malaysia. Asia Pacific Business Review. 10(3/4): 402-421.

UN (2007). Measuring Human Development, A Primer. New York, United Nation

WHO (1946). Constitution of the World Health, World Health Organization.

Wish, N. B. (1986). Are We Really Measuring the Quality of Life? American Journal of Economics \& Sociology. 45(1): 93-99.

Table 1. Health Expenditure Granger Cause GDP

\begin{tabular}{|c|c|c|c|c|c|}
\hline \multirow{2}{*}{ Lagged M } & Indonesia & Malaysia & Philippines & Singapore & Thailand \\
\cline { 2 - 6 } & F-test $(\mathrm{p}$-value $)$ & F-test $(\mathrm{p}$-value) & F-test $(\mathrm{p}$-value) & F-test (p-value) & F-test (p-value) \\
\hline 1 & $9.16(0.00)^{*}$ & $1.90(0.18)$ & $1.20(0.28)$ & $1.81(0.19)$ & $0.67(0.44)$ \\
\hline 2 & $8.54(0.00)^{*}$ & $0.97(0.39)$ & $0.69(0.50)$ & $1.45(0.26)$ & $12.81(0.07)^{* *}$ \\
\hline
\end{tabular}

Table 2. GDP Granger Cause Health Expenditure

\begin{tabular}{|c|c|c|c|c|c|}
\hline \multirow{2}{*}{ Lagged M } & Indonesia & Malaysia & Philippines & Singapore & Thailand \\
\cline { 2 - 6 } & F-test (p-value) & F-test (p-value) & F-test (p-value) & F-test (p-value) & F-test (p-value) \\
\hline 1 & $6.25(0.02)^{*}$ & $3.01(0.09)^{* *}$ & $0.33(0.57)$ & $36.18(0.00)^{*}$ & $5.92(0.05)^{*}$ \\
\hline 2 & $5.72(0.01)^{*}$ & $1.61(0.22)$ & $0.15(0.86)$ & $8.62(0.00)^{*}$ & $1.16(0.46)$ \\
\hline
\end{tabular}

* Statistically significant at $5 \%$ level

** Statistically significant at $10 \%$ level

Table 3. Summary of Granger Causality Test

\begin{tabular}{|l|c|c|}
\hline & Health --- GDP & GDP --- Health \\
\hline Indonesia & $\sqrt{ }$ & $\sqrt{ }$ \\
\hline Malaysia & & $\sqrt{ }$ \\
\hline Singapore & & $\sqrt{ }$ \\
\hline Thailand & $\sqrt{ }$ & $\sqrt{ }$ \\
\hline
\end{tabular}


Table 4. Percentage of Population Living With AIDS/HIV (2005)

\begin{tabular}{|l|c|}
\hline Indonesia & $0.08 \%$ \\
\hline Malaysia & $0.27 \%$ \\
\hline Philippines & $0.01 \%$ \\
\hline Singapore & $0.13 \%$ \\
\hline Thailand & $0.90 \%$ \\
\hline
\end{tabular}

Source: WHO, 2006

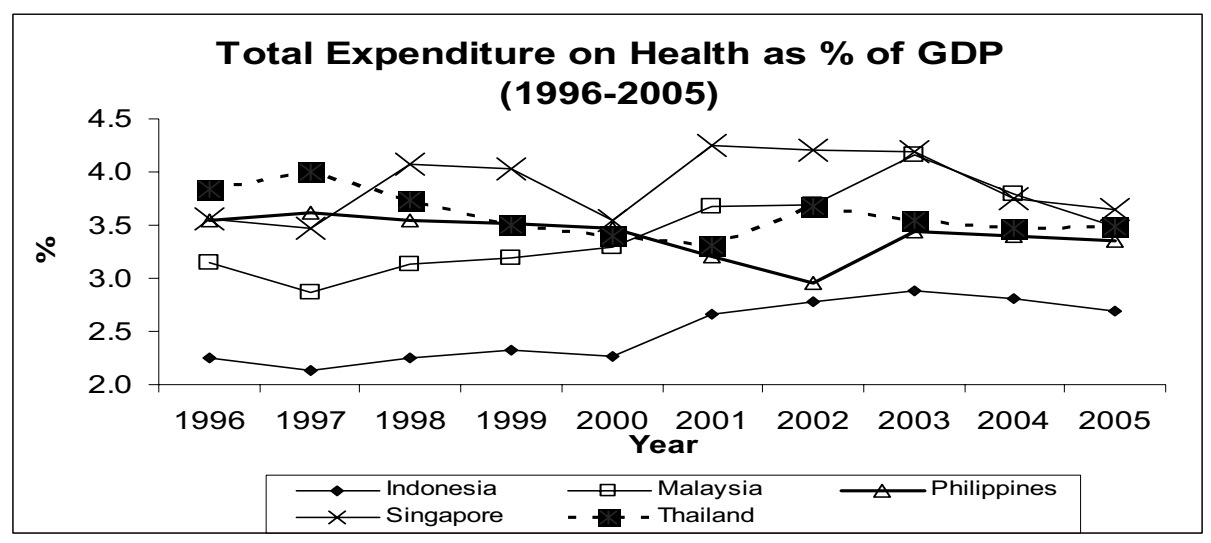

Figure 1.

Source: World Health Organisation

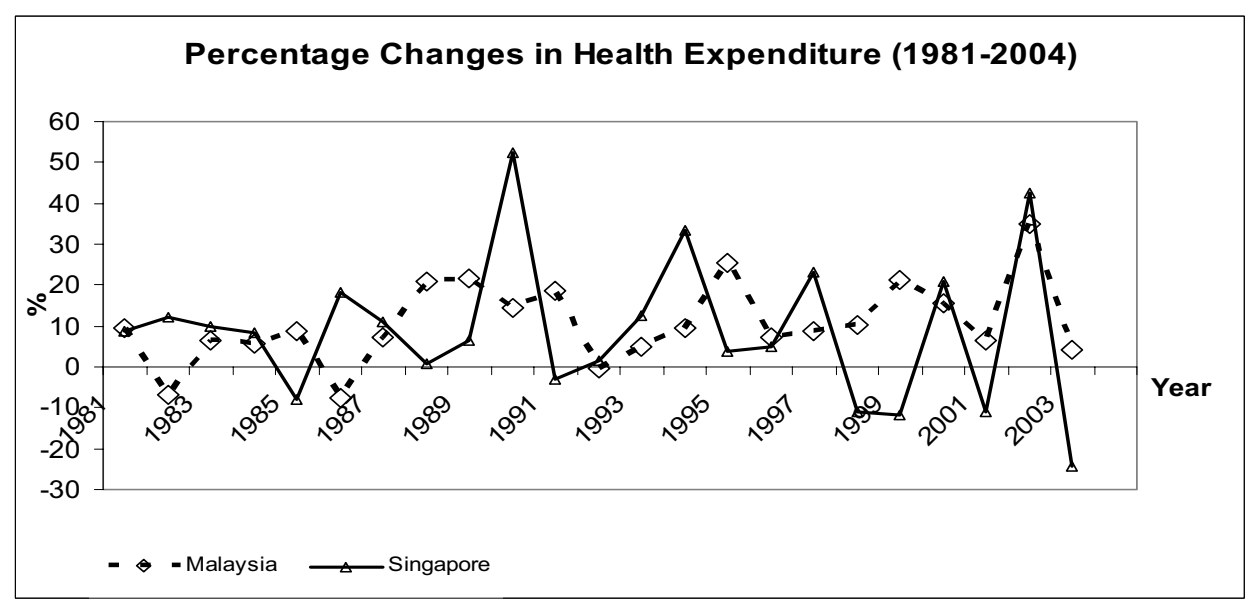

Figure 2. 


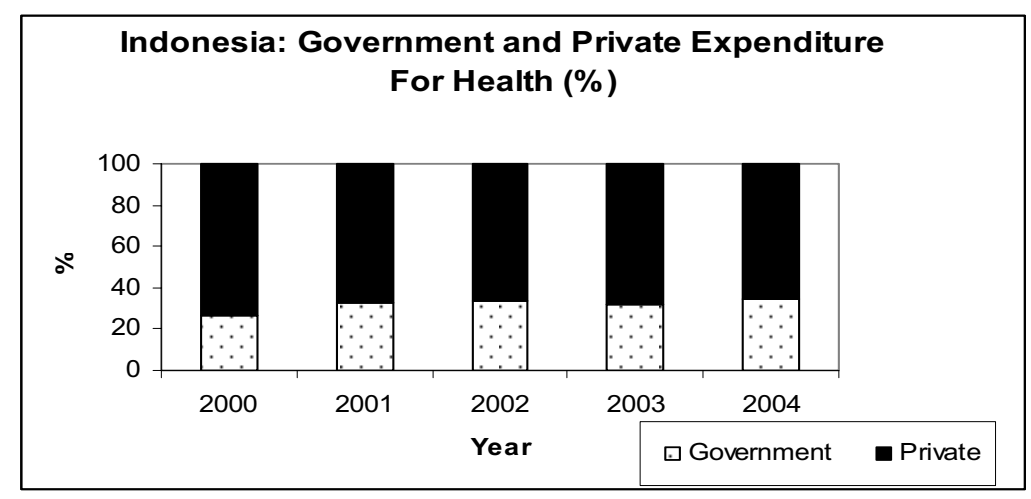

Figure 3.

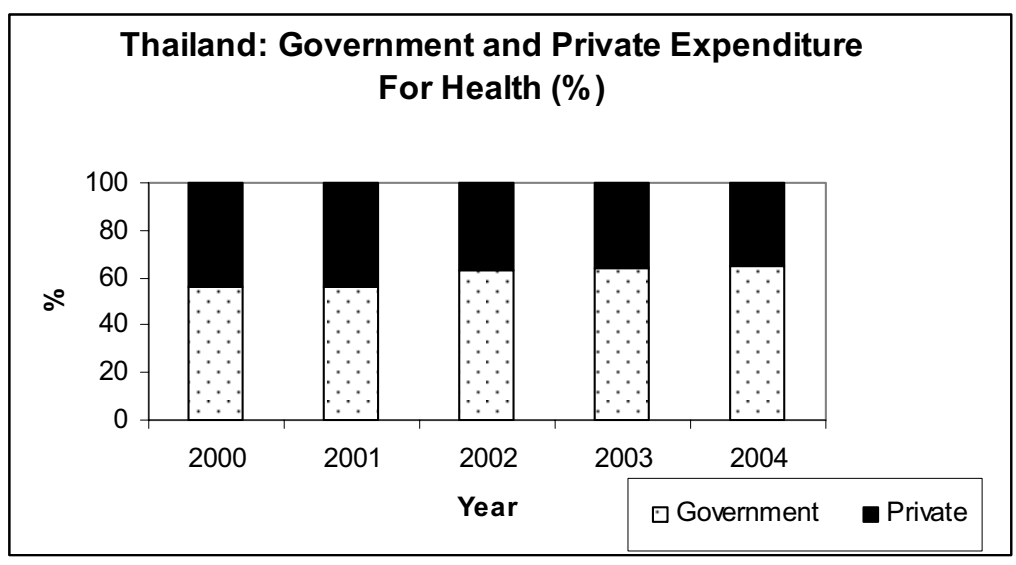

Figure 4. 